\title{
EFFECT OF PRENATAL ADMINISTRATION OF THERAPEUTIC DOSE OF TOPIRAMATE ON PLACENTAE ALBINO RATS' FETUSES
}

\author{
EMAN Y. SALAH EL-DIN' ${ }^{1}$ AMEL R. OMAR*1 \\ 1Department of Zoology, Faculty of Science, Cairo University, Egypt \\ Email: amel_cu1983@yahoo.com
}

Received: 17 Nov 2016 Revised and Accepted: 09 Jan 2017

\begin{abstract}
Objective: Topiramate is an antiepileptic drug (AED) used for the treatment of partial seizure in adult and children epileptic patients. It passed through the placenta causing a birth defect. However, little literature focused on placental alteration due to the administration of topiramate during pregnancy. So, applying different predictive parameters; placental weight, histopathological (Haematoxylin and Eosin), histochemical (periodic acid
\end{abstract} Schiff's) and immunohistochemistry (Caspase-3).

Methods: Topiramate was orally administrated to the pregnant rats with dose $100 \mathrm{mg} / \mathrm{kg}$ rats from $5^{\text {th }}$ to $19^{\text {th }}$ day of gestation. The dam's undergone hysterectomy and the placentae were weighted and stained by Haematoxylin and Eosin, periodic acid Schiff's and Caspase-3.

Results: The study indicated that there is statistically significant $(\mathrm{P}<0.05)$ increase in the treated placental weight $(0.4717 \pm 0.03788)$ compared with control group $(0.5208 \pm 0.02930)$. Also, the light microscopic examination of the placental specimens using Haematoxylin and Eosin staining revealed that an alteration in both basal and labyrinth zone. Apoptotic feature in spongiotrophoblast and trophoblasts is detected. Positive Periodic acid Schiff's reaction for polysaccharides in the topiramate-treated group. Caspase-3 is showing apoptotic cells in the trophoblast layer.

Conclusion: Long-term daily use of topiramate during pregnancy can lead to obvious pathological histotoxic effects in layers of placenta tissues which may be implicated in cognitive affection. Various effects of topiramate necessitate further investigations.

Keywords: Caspase-3, Periodic acid Schiff's, Placenta, Topiramate

(C) 2016 The Authors. Published by Innovare Academic Sciences Pvt Ltd. This is an open access article under the CC BY license (http://creativecommons.org/licenses/by/4. 0/) DOI: http://dx.doi.org/10.22159/ijpps.2017v9i3.16208

\section{INTRODUCTION}

Topiramate chemical structure is 2,3:4,5-Bis-0-(1-methyl-ethylidene)beta-D-fructopyranose sulfamate, its molecular formula is $\mathrm{C}_{12} \mathrm{H}_{21} \mathrm{NO}_{8} \mathrm{~S}$, its molecular weight is $339.36204 \mathrm{~g} / \mathrm{mol}$. It is a secondgeneration antiepileptic drugs (AED) that is classified as 'Pregnancy Category-D drug' in terms of teratogenic risk [1]. In 1996, it was approved by Food and Drug administration (FDA) for the treatment of partial seizure in adult epileptic patients. This drug is also used in children with refractory partial seizures with or without secondary generalised tonic-clonic seizures. This drug reduces of voltage $\mathrm{Na}+$ gates in central nervous system (CNS). It also acts as carbonic anhydrase inhibitor, increases postsynaptic GABA receptor and reduces activation of the kainate subtypes of glutamate receptors [2]. Topiramate is as a Cytochrome P450 3A4 Inducer and Cytochrome P450 2C19 Inhibitor [3]. Also, it was confirmed that topiramate has antidepressant activity in mice [4]

This drug was known to pass the human placenta [5], freely in one to one ratio [6]. Exposure of pregnant women to topiramate (TPM) shows a lower risk of congenital malformations than other antiepileptic drugs [2]. However, major congenital malformations (MCMs) such as oral clefts, hypospadius, skeletal anomalies and others were observed in neonates exposed to it during pregnancy [7].

As reported by the manufacturer (Janssen-Cilag), topiramate was teratogenic in mice, rats and rabbits. Comparable results show an adverse effect of topiramate $(100 \mathrm{mg} / \mathrm{kg} /$ day $)$ on developing embryos in rats increasing a number of resorptions [8].

Long-term daily use of topiramate during pregnancy can lead to neurotoxic effect in the cerebral cortex and hippocampus [9].

Animal studies reported an increased risk of craniofacial defects in litters exposed in utero to low doses of topiramate and other malformations and low birth weight at higher doses.15 some postmarketing studies in pregnant women have suggested an increased risk in birth defects overall and, possibly, an increased risk in cleft lip with or without cleft palate (CL/P); however, data was inconclusive because neither the exposure nor oral clefts are frequent [10-13].

Topiramate, administered orally at 40, 100 and $200 \mathrm{mg} / \mathrm{kg}$ doses from days 9 to 12 of gestation produced skeletal anomalies in Charles Foster rats fetuses in a dose-related manner, but the fetal weight was not reduced [14]. In addition, children, whose mother received topiramate throughout pregnancy, were born with bone abnormalities in their thumbs and toes [15]. It was reported that topiramate administration during pregnancy caused congenital absence of all or part of a digit (ectrodactyly) in rats and rib and vertebral malformations in rabbits [16]. Also, fetal growth restriction and increases abnormalities of axial skeleton in rat fetuses [17].

The relationships between the mother and fetus are very complex; these relations occur through the placental tissue and control development of the fetus. The exchange between maternal and fetal blood occurs across the labyrinth layers of the placental barrier. In rats the placenta consisted of two parts: the maternal part and the embryonic one. The later develops by the evolution of the villous chorion, and the maternal part originates from the main deciduas which consider the most important channel for the materials exchange between the maternal and fetal bloods. So, the placenta was a target organ for drug or chemical-induced adverse effects. Drug-or chemical-induced placental functional depression and injury subsequently result in abnormal fetal growth or development leading to delay in growth of fetuses, fetal resorption and teratogenicity.

Apoptosis was a highly regulated and intrinsic cell suicide program that is important in both physiological and pathological conditions. The central component of apoptosis was a family of proteases called caspases. Cysteine aspartate-specific proteases, known as caspases, were divided into two groups: initiator caspases, such as Caspase-8, and-9, whose main function was to activate downstream executioner 
Caspases, such as Caspase-3,-6 and-7, which were responsible for degradation of cellular proteins [18].

To detect the glycogen content in the placenta, the histochemical staining was applied; Periodic acid Schiffs to identify poly-saccharides.

However, there are no much available reports concerning topiramate teratogenic potential in humans. This could be explained by a limited number of pregnancies exposed. Very few reports available are on animal experimentation with controversial results. Therefore, topiramate was selected in this study to evaluate its effects, if any, on the placenta.

\section{MATERIALS AND METHODS}

\section{Drug used}

Topiramate tablet $(100 \mathrm{mg})$ is used in the treatment of obesity; migraine prevention; fibromyalgia; diabetic peripheral neuropathy; seizure prevention. It was purchased from Kahira pharmaceutical company, Cairo, Egypt. Each tablet contains $100 \mathrm{mg}$ of topiramate.

\section{Animal housing}

Virgin female and male albino rats, Rattus norvegicus, weighing about $170-180 \mathrm{~g}$ were used in the present investigation. The animals were obtained from the animal house of the Faculty of Veterinary Medicine, Giza, Egypt. Before starting the experiment, animals were allowed to acclimatize for at least $7 \mathrm{~d}$. Pregnancy was established by housing females in the pro-estrous and oestrous stages with healthy fertile males overnight; 12 -h light/dark cycle (2:1) under controlled of temperature $\left(25 \pm 2{ }^{\circ} \mathrm{C}\right)$, humidity $(60 \pm 20 \%)$ and given feed and water ad libitum. The next morning, females with a positive vaginal plug or vaginal smears were considered pregnant, and the day of detection was defined as the first day of pregnancy or gestation [19, 20]. Experimental protocols and procedures used in this study were approved by the Cairo University, Faculty of Science, and Institutional Animal Care and Use Committee (IACUC) (Egypt). The animals were handled according to the Guide for the Care and Use of Laboratory Animals, $8^{\text {th }}$ Edition (2011 National Academies Press).

\section{Experimental design and animal treatment}

Pregnant rats were divided into two groups (12 per group). The control group received tape water, and the experimental groups received $100 \mathrm{mg} / \mathrm{kg}$ of topiramate diluted in tape water. The dosing regimen was based on human therapeutic dose (HED). Treatments were administered orally by gavage from day 5 up to 19 of pregnancy, defined as the critical period for the structural development span of the embryonic stage for rats [21]. At the $20^{\text {th }}$ of gestation, each dam was submitted to cesarean section. The animals were anaesthetized with sodium pentobarbital. Fetuses recovered through caesarean section were removed from their membranes and were separated from their placentae. The latter weights were recorded.

\section{Histopathological studies}

Placenta of the control and treated groups were firstly fixed for histological investigation by light microscopy using; $10 \%$ formalin solution for $24 \mathrm{~h}$. washing was done in running water to remove excess fixative then dehydration using serial ascending series of ethyl alcohol. Specimens were cleared in xylene and embedded in paraffin wax at 56 degrees in hot air oven. Paraffin wax tissue blocks were prepared for sectioning at $5 \mu$ thicknesses using Reichert microtome. The obtained tissue sections were mounted on glass slides, deparaffinized, stained with Haematoxylin (Ehrlich) and counterstained by Eosin for routine examination then examination was done through the light electric microscope [22]. For histochemical study specimens were fixed in Carnoy's fluid. Periodic acid Schiff's reaction was used for demonstration of polysaccharides [23]. For immunehistochemistry examinations were used Caspase-3 (apoptotic marker), positive cells were determined with streptavidin-biotin-peroxidase staining method [24].

\section{Statistical analysis}

Results were expressed as mean \pm SD All statistical analysis were done using Statistical Package for the Social Sciences (SPSS) (version 20 ), the T-test was performed to test the significance level between the treated groups and negative control group. Values of $\mathrm{P}<0.05$ were considered statistically significant. The data analysis was performed using SPSS version 15.0.

\section{RESULTS}

\section{Placental toxicity}

The placenta is a temporary organ; it is an interface between the dam and developing embryos and a complex organ that have important roles that are modified throughout gestation period. The pregnant dams treated with $100 \mathrm{mg} / \mathrm{Kg}$ of topiramate drug showing a significant increase in the placental weight $(0.74 \pm 0.03)$ compared to control group $(0.52 \pm 0.02)$ as shown in (fig. A).

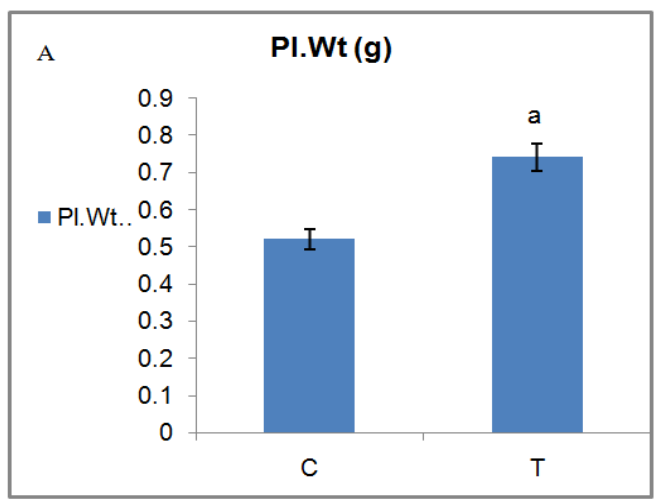

Fig. A: Showing the topiramate effect on placenta weight at $20^{\text {th }}$ day of gestation (a: significant $\mathrm{p}<0.05$ ), $\mathrm{Pl}$. Wt (g): the placenta weight in grams, (C): control group, (T): group treated with $100 \mathrm{mg} / \mathrm{kg} / \mathrm{day}$ of topiramate and the values expressed by mean \pm SD

\section{Histopathological observations}

The microscopic examination of the placenta treated with TPM, an increase in a basal layer with a decrease of labyrinth zone of the placenta are recorded in comparison with control one (fig. 1). Histopathologically, placental necrosis and degeneration appear more commonly in the trophoblasts in the labyrinth zone (fig. 2). There is a reduction in thickness and disruption of the trophoblastic septa and irregular dilatation of maternal sinusoids with hemorrhagic sites (fig. 3 ). Enlarged maternal blood vessels with an increase in thickness of its endothelium are observed, this maternal blood vessel surround by bloody evidence (fig. 4). While the fetal blood vessels show degree of damage of endothelium (fig. 5).

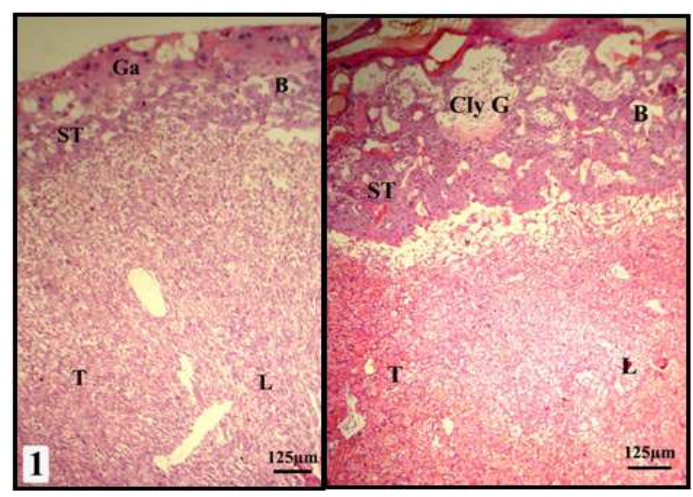

Fig. 1: Section of placenta stained with Haematoxlin and Eosin stain. Left fig. is the control pregnant rat showing normal basal zone (B), normal labyrinth zone (L), giant cell (Ga), spongiotrophoblast (ST). Right is the treated one demonstrating increasing in the basal zone (B) and decrease in the labyrinth zone (L), (Ga): giant cell, (ST): spongiotrophoblast, (T): trophoblast 
In the basal zone, necrotic areas are detected. Also, the nuclei of spongiotrophoblast are characterised by karyorrhexis (fig. 6). An increase in numbers of glycogen cells are recorded, this glycogen cells undergo cytolysis and subsequently coalesce into multiple large cysts that are filled with a homogeneous acidophilic mass, and multiple clusters of residual glycogen granules, macrophages, erythrocytes and cell debris, Hyperemia (hemorrhagic cysts) was observed (fig. 7). The decrease in a number of major endocrine giant trophoblastsin comparison with control one (fig. 1). In addition, nuclei of it were characterised by pyknosis and odd shaped. Heterogenous cytoplasmic vacuoles of giant cells are evidence (fig. 8).

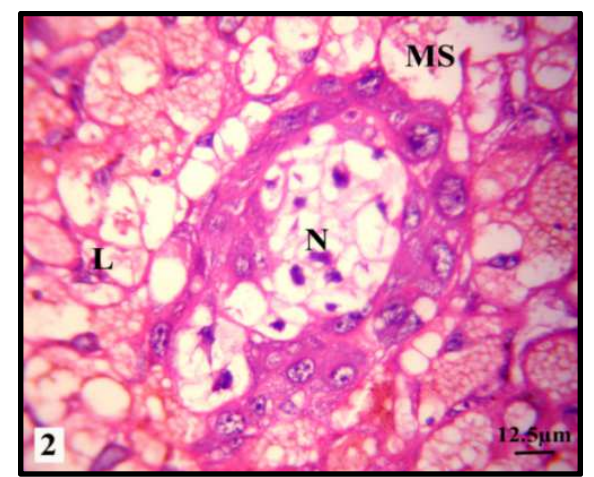

Fig. 2: Section of treated placenta stained with Haematoxylin and Eosin stain showing necrotic areas $(\mathrm{N})$ in the labyrinth zone (L) and maternal sinusoid (MS)

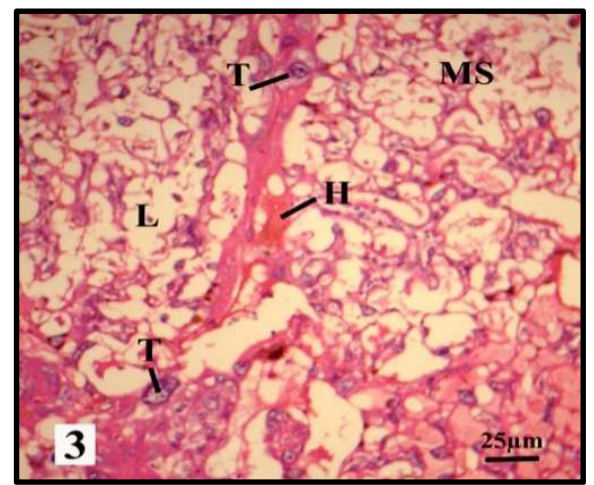

Fig. 3: Section of treated placenta stained with Haematoxylin and Eosin stain showing hemorrhagic areas $(\mathrm{H})$ and dilation in the maternal sinusoid of labyrinth zone (L), (T): Trophoblast, (MS): maternal sinusoid

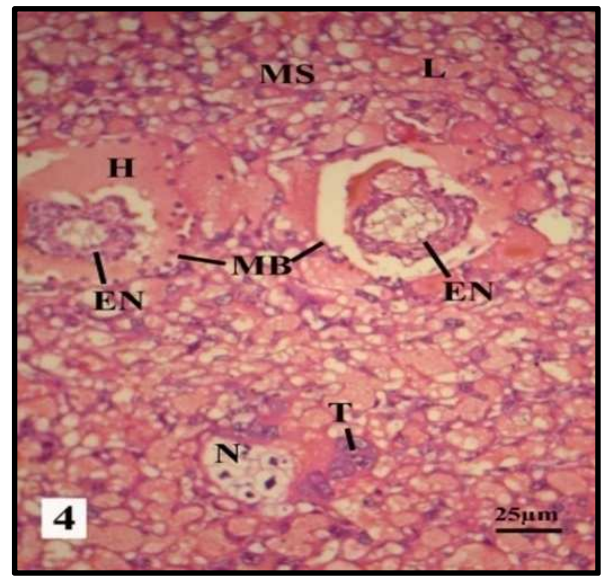

Fig. 4: Section of treated placenta stained with Haematoxylin and Eosin stain showing enlargement of the maternal blood vessels (MB) with increased the thickness of endothelium of the maternal blood vessels (EN), (H): hemorrhagic areas, (MS): maternal sinusoid, $(\mathrm{T})$ : trophoblast, $(\mathrm{N})$ : necrotic area

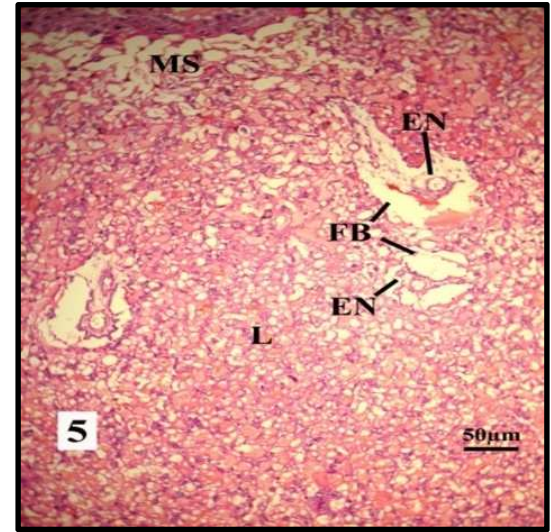

Fig. 5: Section of treated placenta stained with Haematoxlin and Eosin stain illustrating damage in the endothelium of fetal blood vessels (FB), (EN): maternal blood vessels, (L): labyrinth zone, (MS): maternal sinusoid

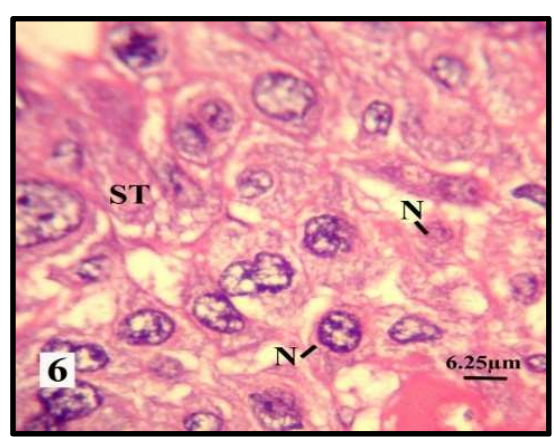

Fig. 6: Section of treated pregnant rat's placenta stained with Haematoxylin and Eosin stain, showing some necrotic areas (N) in the basal zone, (ST): spongiotrophoblast

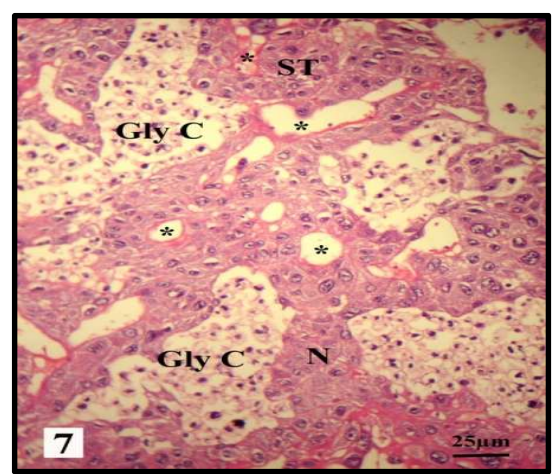

Fig. 7: Section of treated pregnant rat's placenta stained with Haematoxylin and Eosin stain, showing cytolysis of glycogen cells (Gly C) and hemorrhagic cysts (stars), (N): necrotic areas

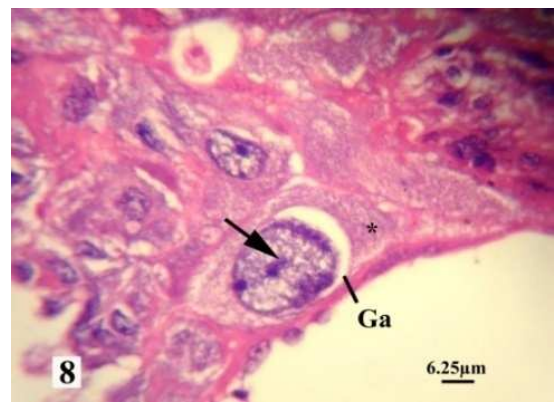

Fig. 8: Section of treated pregnant rat's placenta stained with Haematoxylin and Eosin stain, showing alteration in nucleus (arrow) and cytoplasmic vacuoles of giant cells (Ga) (star) 


\section{Histochemical examination}

The light microscopic investigation revealed that the placental tissue of the treated group showed positive Periodic acid Schiffs (PAS) reaction; specially coalesce glycogen cells (fig. 9) and spongio-trophoblasts of the basal zone (fig. 10), trophoblasts of labyrinth zone (fig. 11).

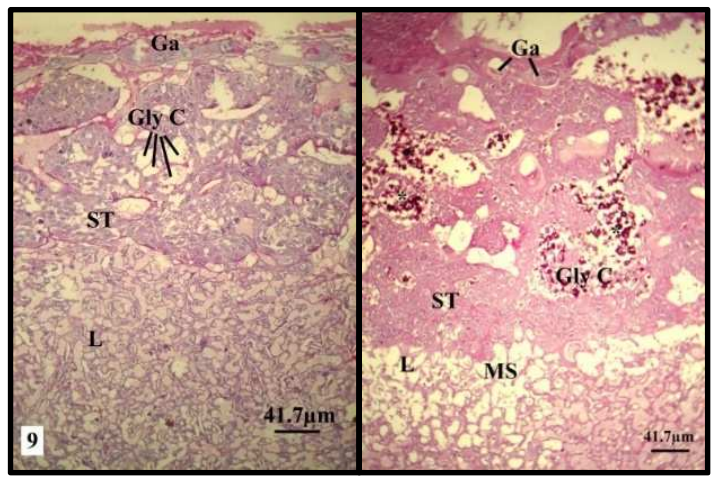

Fig. 9: Section of pregnant rat's placenta stained with Periodic acid Schiff's. Left fig. is controlled; normal tissue structure, (Gly C): cytolysis of glycogen cells, (Ga): giant cell, (ST): spongiotrophoblast, (L): labyrinth zone. Right treated showing a positive reaction of Periodic Acid-Schiff's (PAS) in glycogen cells (Gly C), (Ga): giant cell, (ST): spongiotrophoblast, (L): labyrinth zone, (MS): maternal sinusoid

\section{Immunohistochemical investigation}

Also, different degree of the apoptotic index in trophoblasts is recorded using Caspase-3 as an indicator (fig. 12).

\section{DISCUSSION}

The relationships between the mother and fetus are very complex; these relations occur through the placental tissue and control development of the fetus. So, the placenta is the principle link between mother and its fetus, being responsible for the transfer of nutrients from maternal to fetal blood and for the clearance of waste metabolites from fetal blood across the labyrinth layers of the placental barrier. In addition, the placenta is a target organ for drug or chemical-induced adverse effects. Drug or chemical induced placental functional depression and injury subsequently result in abnormal fetal growth or development leading to delay in growth of fetuses, fetal resorption and malformation. It is worthy to mention that; placenta is thus determinant for pregnancy success.

This is the first record showing that prenatal administration of topiramate causes a developmental alteration in the rat placental tissue. In Charles Foster rats fetuses, topiramate was administered orally at 40,100 and $200 \mathrm{mg} / \mathrm{kg}$ doses from days 9 to 12 of gestation produced skeletal anomalies in a dose-related manner, but the fetal weight was not reduced $[13,25]$. In contrary, maternal body weight was reduced significantly following administration of different doses of antiepileptic drugs in experimental animals [26, 27]. The increase in placenta weight with significance difference in this study may be to the maternal nutritional status. Although topiramate shows some promise as a therapeutic agent in epileptic pregnant women with lower risk of a teratogenic effect than other drugs [2] there are reports of its teratogenic effects in animals $[15,28]$. Multiple sites of toxicity acting along the hypothalamic-pituitary-ovarian-uterine axis due to TPM administration explain the malformation in mother, fetuses and placenta. In second-generation antiepileptic drugs, during pregnancy hormonal changes, that is, increased estrogen levels, lead to accelerated drug glucuronidation in the liver. This condition appears to increase gradually throughout the first and second trimester, with little change during the last trimester [29]. Also, the activity of some CY P450 enzymes is increased [30].

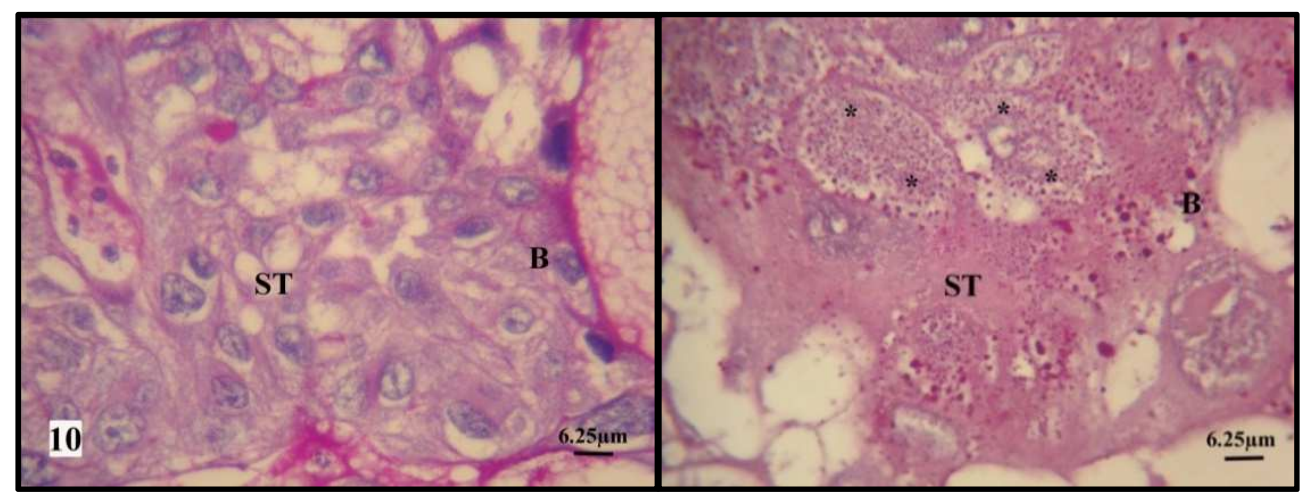

Fig. 10: Section of pregnant rat placenta stained with Periodic acid Schiff's. left is control; normal spongiotrophoblast (ST) of the basal zone (B). Right showing a positive reaction of Periodic acid Schiff's (PAS) in spongiotrophoblast (ST) of basal zone (B) (stars)

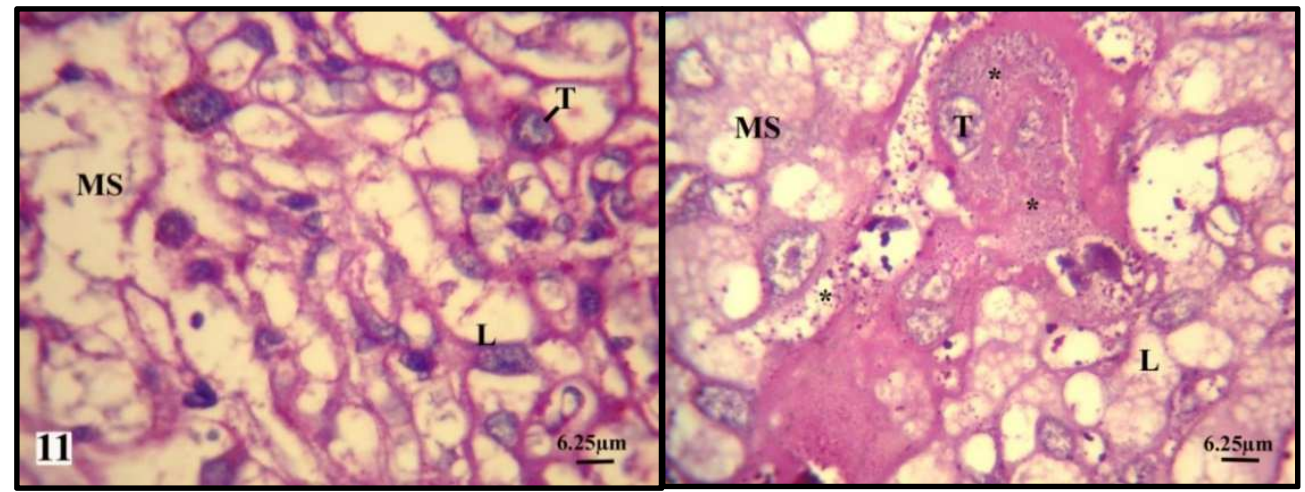

Fig. 11: Section of pregnant rat's placenta stained with Periodic acid Schiff's, (L): labyrinth zone, (MS): maternal sinusoid, (T): trophoblast. Left is normal control structure of trophoblasts (T) of labyrinth zone (L). Right treated showing a positive reaction of Periodic acid Schiff's (PAS) in trophoblasts (T) of labyrinth zone (L) (stars) 


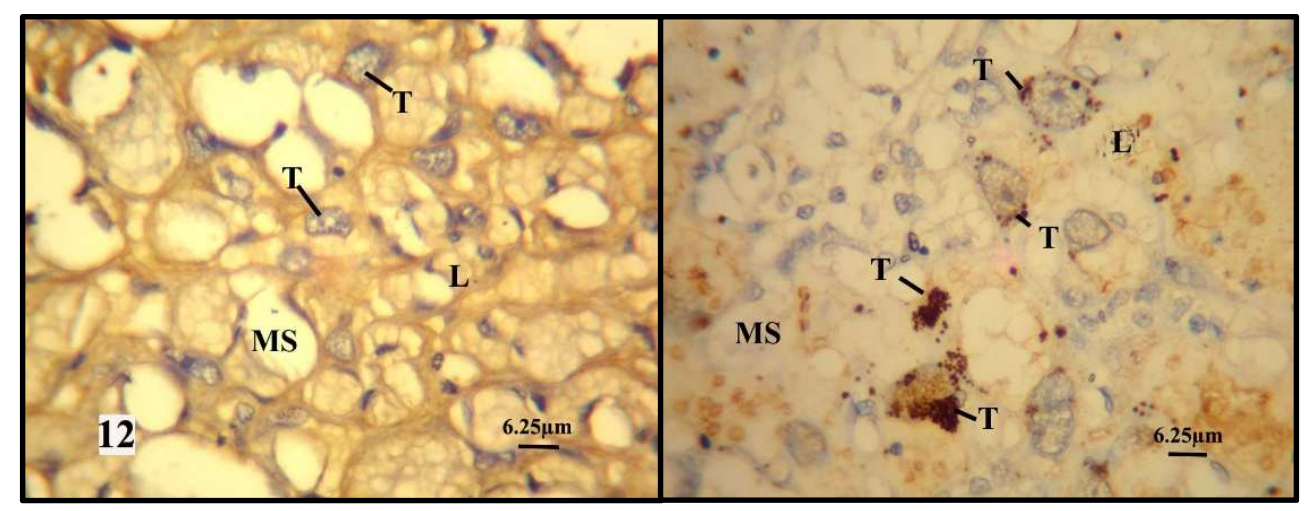

Fig. 12: Section of pregnant rat placenta stained with Caspase-3 immunostain. Left fig. is control, showing the negative reaction of caspase3 of trophoblast cells (T), (L): labyrinth zone, (MS): maternal sinusoid. Right fig. is treated, showing apoptosis of trophoblasts (T) in the labyrinth zone (L), (MS): maternal sinusoid

Multiple physiological pathways have been affected by topiramate. The main mechanism of teratogenic action which affects on different tissue in the body is oxidative stress $[31,32]$. Topiramate was found to be a free radical scavenger [33] and its role as antioxidant indicates that its effect on placenta is not due to the presence of free radicals [16]. On the contrary, in this study, oxidative damage causes as an increase in caspase-3 activity as indicated in this manuscript, which would lead to increased apoptosis of cells [34], the oxidative damage is a result of the imbalance of free radicals production and antioxidant capacity. Mechanism of action of valproic acid is related to the changes in methylation of histones [35].

Epigenetic modification of them with hyperacetylation is accompanied with induction of apoptosis [36, 37]. The latter condition may be occurring in placental tissue causing a defect in its structure as well as its function.

TPM affects cell polarisation through effects on various ion channels [38]. It inhibits histone deacetylases; histone deacetylases are also inhibited by valproic acid [39]. In previous studies, treatment with topiramate was associated with metabolic acidosis due to its inhibitory action on carbonic anhydrase enzyme [40,41], which leads to renal bicarbonate loss $[42,43]$. These mechanisms may lead to alteration on the tissue of placenta in the present study.

\section{CONCLUSION}

Generally, the teratogenic mechanism of AEDs is only partially understood. So, it may be essential to study the effect of topiramate on similar signalling pathways that are altering different body tissue.

\section{ACKNOWLEDGEMENT}

This paper was supported by Zoology Department, Faculty of Science, Cairo University.

\section{CONFLICT OF INTERESTS}

The authors report no conflict of interest. The authors alone are responsible for the content and the writing of the paper

\section{REFERENCES}

1. Harden CL, Meador KJ, Pennell PB, Hauser WA, Gronseth GS, French JA, et al. American academy of neurology; American epilepsy society, management issues for women with epilepsyfocus on pregnancy (an evidence-based review): II. teratogenesis and perinatal outcomes: report of the quality standards subcommittee and therapeutics and technology subcommittee of the American academy of neurology and the American epilepsy society. Epilepsia 2009;50:1237-46.

2. Palmieri C, Canger R. Teratogenic potential of newer antiepileptic drugs: What is known and now should this influence prescribing. CNS Drugs 2002;16:755-64.

3. Preissner S, Kroll K, Dunkel M, Senger C, Goldsobel G, Kuzman $\mathrm{D}$, et al. A comprehensive database on cytochrome P450 enzymes including a tool for analysis of CYP-drug interactions. Nucleic Acids Res 2010;38:D237-43.

4. Aithal S, Hooli TV, Patil R, Varun HV, Swetha ES. Evaluation of the antidepressant activity of topiramate in mice. Asian J Pharm Clin Res 2014;7:174-6.

5. Gentile S. Topiramate in pregnancy and breastfeeding. Clin Drug Investig 2009;29:139-41.

6. Ohman I, Vitols S, Luef G, Söderfeldt B, Tomson T. Topiramate kinetics during delivery, lactation, and in the neonate: preliminary observations. Epilepsia 2002;43:1157-60.

7. Fountain NB. A pregnant pause to consider teratogenicity of topiramate. Epilepsy Curr 2009;9:36-8.

8. Khouri NA. Reproductive toxic effects of Topamax ingestion in female sprangue dawley rats. Neuroendocrinol Lett 2005; 26:843-7.

9. Hagar AH. Histopathologic effect of prenatal topiramate exposure on rat cerebral cortex and hippocampus. J Interdiscipl Histopathol 2014;2:61-8.

10. Bender P. Genetics of cleft lip and palate. J Pediatric Nursing 2000;15:242-9.

11. Molgaard-Nielsen D, Hviid A. Newer-generation antiepileptic drugs and the risk of major birth defects. JAMA 2011;305:1996-2002.

12. Vajda FJ, Hitchcock A, Graham J, O’Brien T, Lander C, Eadie M. The Australian register of antiepileptic drugs in pregnancy: the first 1002 pregnancies. Aust N Z J Obstet Gynaecol 2007; $47: 468-74$

13. Hernandez-Diaz S, Mittendorf R, Holmes LB. Comparative safety of topiramate during pregnancy. Birth Defects Res Part A 2010;408:20

14. Singh M, Mishra A. Topiramate induced congenital malformations in rats. Natl Acad Sci Lett 2009;32:195-200.

15. Vila Cerén C, Demestre Guasch X, Raspall Torrent F, Elizari Saco MJ, Sala Castellví P, Martínez Nadal S. Topiramate and pregnancy. Neonate with bone anomalies. Annals Pediatrics (Barc) 2005;63:363-5.

16. Kwarta RF, Hulihan JF, Schmider J, Nye JS. Pregnancy outcomes in topiramate-treated women. Epilepsia 2006;47:119-204.

17. Fadel RA, Sequeira RP, Abu-Hijleh MF, Obeidat M, Salem AHA. Effect of prenatal administration of therapeutic doses of topiramate on the ossification of ribs and vertebrae in rat fetuses. Rom J Morphol Embryol 2012;53:321-7.

18. Creagh EM, Martin SJ. Caspase: cellular demolition experts. Biochem Soc Trans 2001;29:696-702.

19. McClain RM, Becker BA. Teratogenicity, foetal toxicity and placental transfer of lead nitrate in rats. Toxicol Appl Pharmacol 1975;931:72-82.

20. El-Ghareeb AA, Salah EL-Din EY, Omar AR, Atallah SE. Evaluate the effect of oral administration of Salvia officinalis extracts on albino rats' fetuses during the gestation period. Int J Adv Life Sci 2016;9:307-15.

21. WHO (World Health Organization). Principles for evaluating health risks to reproduction associated with exposure to chemicals. Environ Health Criteria 2001;225:1-187. 
22. Banchroft JD, Stevens A. The haematoxylin and eosin. Theory and practice of histological techniques. 4th ed. London, New York, Tokyo: Churchill Livingstone 1996. p. 99-112.

23. Kiernan JA. Histological and histochemical methods: Theory and practice. Pergamon Press Inc New York USA; 1981.

24. Karakus EA, Karadeniz N, Simsek I, Can KA, Kara A, Yildirim $\mathrm{S}$, et al. Protective effect of panax ginseng against serum biochemical changes and apoptosis in the liver of rats treated with carbon tetrachloride (CCl4). J Hazard Mater 2011; 195:208-13.

25. Singh M, Mishra A. Teratogenicity of topiramate in rats. J Am Soc Inf Sci Technol 2005;54:206.

26. Fadel RA, Dessouki SKM, Mostafa NMM, Dawoud AWAK. Skeletal development in albino rat fetuses following maternal exposure to diazepam. Egyptian J Anat 2002;25:233-55.

27. Saillenfait AM, Gallissot F, Sabaté JP. Developmental toxic effects of N-ethyl-2-pyrrolidone administered orally to rats. J Appl Toxicol 2007;27:491-7.

28. Glauser TA. Topiramate. Epilepsia 1999;5:71-80.

29. Reimers A, Helde G, Bråthen G, Brodtkorb E. Lamotrigine and its $N 2$-glucuronide during pregnancy: the significance of renal clearance and estradiol. Epilepsy Res 2011;94:198-205.

30. Anderson GD. Pregnancy-induced changes in pharmacokinetics: a mechanistic-based approach. Clin Pharmacokinet 2005;44:10-1008.

31. Ornoy A, Rand SB, Bischitz N. Hyperglycemia and hypoxia are interrelated in their teratogenic mechanism: studies on cultured rat embryos. Birth Defects Res Part B 2010;89:106-15.

32. Fadel RAR, Omar MM, Issa FI, Badr FM. Effects of melatonin on the teratogenicity of alcohol in the albino rat. Suez Canal University Med J 1999;2:173-86.

33. Naziroğlu M, Kutluhan S, Uğuz AC, Celik O, Bal R, Butterworth PJ. Topiramate and vitamin $\mathrm{E}$ modulate the electroencephalographic records, brain microsomal and blood antioxidant redox system in the pentylenetetrazol-induced seizure of rats. J Membr Biol 2009;229:131-40.

34. Chen YS, Lim SC, Chen MH, Quinlan RA, Perng MD. Alexander disease-causing mutations in the C-terminal domain of GFAP are deleterious both to assembly and network formation with the potential to both activate caspase 3 and decrease cell viability. Exp Cell Res 2011;317:2252-66.

35. Tung EWY, Winn LM. Epigenetic modification in valproic acidinduced teratogenesis. Toxicol Appl Pharmacol 2010;248:201-9.

36. Menegola E, Di Renzo F, Broccia ML, Prudenziati M, Minucci S, Massa $\mathrm{V}$, et al. Inhibition of histone deacetylase activity on specific embryonic tissue as a new mechanism for teratogenicity. Birth Defect Res Part B 2005;74:392-8.

37. Di Renzo F, Broccia ML, Giavini E, Menegola E. VPA-related axis skeletal defects and apoptosis: a proposed event cascade. Reprod Toxicol 2010;29:106-12.

38. Margulis AV, Mitchell AA, Gilboa SM, Werler MM, Mittleman MA, Glynn RJ, et al. Use of topiramate in pregnancy and risk of oral clefts. Am J Obstet Gynecol 2012;207:1. e1-1. e7.

39. Martínez-Frías ML. Topiramate in pregnancy: preliminary experience from the UK epilepsy and pregnancy register. Neurology 2009;72:2054-5.

40. Tata AL, Kockler DR. Topiramateforbingeeating disorder associated with obesity. Ann Pharmacother 2006;40:1993-7.

41. McNamara J0. Pharmacotherapy of the epilepsies. Chapter 19. In: Brunton LL, Parker KL, Murri N. eds. Goodman and Gilman's the pharmacological basis of therapeutics, 11e. Available from: http://www.accessmedicine.com.ezp-prod1.hul.harvard.edu/ content.aspx?aID939716. [Last accessed on 20 Dec 2011]

42. Mirza N, Marson AG, Pirmohamed M. Effect of topiramate on acid-base balance: extent, mechanism and effects, $\mathrm{Br} \mathrm{J}$ Clin Pharmacol 2009;68:655-61.

43. Paul E, Conant KD, Dunne IE, Pfeifer HH, Lyczkowski DA, Linshaw MA, et al. Urolithiasis on the ketogenic diet with concurrent topiramate or zonisamide therapy. Epilepsy Res 2010;90:151-6.

\section{How to cite this article}

- Eman Y Salah EL-DIN, Amel R Omar. Effect of prenatal administration of a therapeutic dose of topiramate on placentae albino rats' fetuses. Int J Pharm Pharm Sci 2017;9(3):54-59. 